\title{
Seven-year grant offers immune tolerance a boost
}

Translational research - research aimed at getting promising ideas out of the lab and into the clinic - is a hot topic in biomedical circles, not least because it is a favourite theme of Elias Zerhouni, director of the US National Institutes of Health (NIH). But if it is hot, it's also hard. That, at least, is the experience of the NIH's Immune Tolerance Network (ITN), a consortium of researchers trying to apply some basic immunology to making patients better.

The ITN was originally set up in 1999 with a budget of $\$ 165$ million; on 2 May the NIH renewed its contract with $\$ 220$ million for the next seven years. But the field is still trying to overcome substantial roadblocks, ranging from problems in setting up clinical trials to significant scientific difficulties.

Immune tolerance is the process by which the body avoids launching immune attacks against its own tissues, and the ITN's idea is to harness it

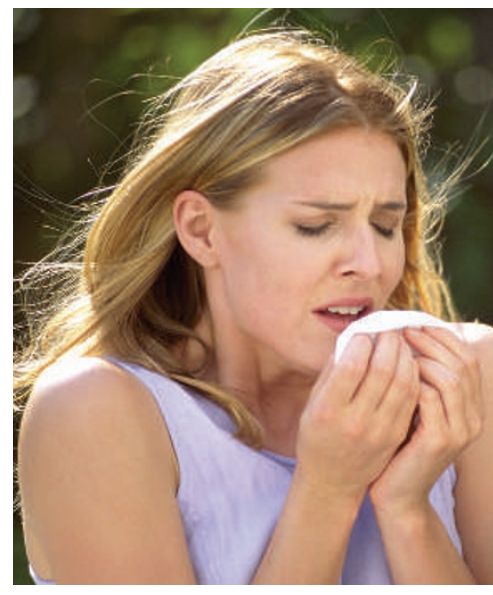

Could allergies be made more tolerable?
Three of those patients now survive with no immunosuppressive drugs, and no patient lost a kidney (Y. Fudaba et al. Am. J. Transplant. 6, 2121-2133; 2006). "This is the first time anyone has intentionally tried to induce tolerance in transplant patients, and it worked," Sykes says.

A follow-up clinical trial didn't pan out, however. Sykes could not recruit enough patients and so the ITN ended its support last year. She is now part of a team that the ITN is funding to test the same approach with the more numerous kidney-transplant patients who don't have cancer.

A follow-up to a successful ITN-funded trial of an allergy treatment was also cancelled after almost a year of planning. "Our original trial was one of two ITN-sponsored studies that got published in the New England Journal of Medicine," says Peter Creticos of Johns Hopkins to curb the destructive immune reactions that underlie conditions ranging from organ transplant rejection to type I diabetes.

Not surprisingly, drug companies have shown little interest in an idea that aims at eliminating patients' long-term need for pharmaceuticals such as immunosuppressants or, indeed, insulin. Although Europe and Canada have smaller consortia devoted to the same end, the ITN, which is also funded in part by the Juvenile Diabetes Research Foundation, is the largest effort to take tolerance into the clinic.

The approach has had some successes. In one notable trial, which was already under way when the ITN began to fund it, a team led by immunologist Megan Sykes at the Massachusetts General Hospital in Boston carried out simultaneous transplants of bone marrow and kidneys from the same donor to six cancer patients with kidney failure, who in any case needed bone marrow. The idea was that the bone marrow would become integrated into the recipient's immune system and make it see the transplanted kidney as its own tissue rather than as an interloper.
University (P. S. Creticos et al. N. Engl. J. Med. 355, 1445-1455; 2006). "We helped them win that renewal, and then they pulled the plug."

ITN director Jeffrey Bluestone, of the University of California, San Francisco, admits that the network has had to make some hard decisions. He says the trial that Creticos was involved in was cancelled because it didn't recruit enough patients. "I truly regret that we weren't able to pull it off," Bluestone says.

But of equal concern to Bluestone are the scientific difficulties the ITN has encountered. Many treatments that worked like a charm in mice haven't worked out in further tests. $\mathrm{He}$ thinks the future of tolerance will not rely on the use of single drugs, which will complicate future trials even further. The ITN completed just seven of its 23 planned trials during its first contract, and cancelled three. A further eight trials are now in the works. Yet Bluestone says, "I wake up every morning with this dream that we'll bring some of these therapies to fruition." It's a noble dream, and slightly closer to reality than it was seven years ago.

Erika Check

\section{SCORECARD}

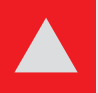

Beer

Australian brewer Foster's is planning

to install a 2,500-litre bacterial fuel cell at its Brisbane plant, to produce clean energy from sugary waste water...

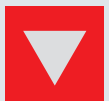

Beer

...While German drinkers are facing

the sobering prospect of a price hike for their favourite brew, as many of the country's barley farmers are switching to heavily subsidized biofuel crops.

\section{ON THE RECORD}

\section{'CA scientist by day, he is a lead Chippendale dancer by night.")}

Promotional material for the US reality-TV show Pirate Master describes John Lakness, who will compete with 15 others for a \$1million prize. Lakness reportedly studied electrical engineering at Rensselaer Polytechnic Institute.

\section{HOBBIT NEWS}

\section{Fossil fiction}

Homo floresiensis fans will be excited to learn that the tiny hominins have spawned a novel, Flores Girl - and it's free to download at www.floresgirl.com. Author Erik John Bertel promises that a sequel is already under way.

\section{ZOO NEWS}

\section{Rhino record}

Emi, a Sumatran rhino at Cincinnati Zoo, has given birth to a record-breaking third calf (pictured). The proud mum is the first of this species to bear more than a single calf in captivity.

Sources: Associated Press, Czech Business Weekly,
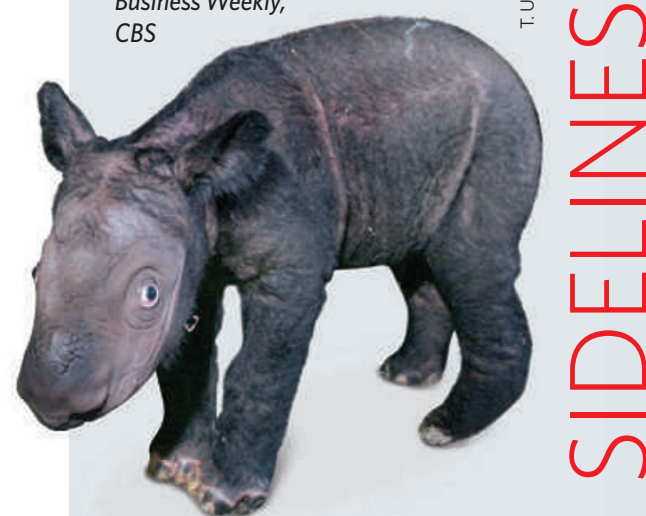